\title{
Improvement of Dissolution Rate of Chlorzoxazone by Solid Dispersion Technique and Development of Buccal Patch
}

\author{
Swati Jagdale*, Asawaree Hable, Aniruddha Chabukswar and Bhanudas Kuchekar
}

\author{
MAEER's Maharashtra Institute of Pharmacy, S. No. 124, MIT Campus, Paud Road, Kothrud, Pune-411038, \\ India
}

\begin{abstract}
Chlorzoxazone (CLZ) is insoluble in water. Its half life is $1.1 \mathrm{hr}$, dose is $250 \mathrm{mg}$ and has first pass metabolism. Formation of solid dispersions of CLZ with pluronic F127 will enhance the bioavailability of the drug. Phase-solubility studies revealed $A_{L}$ type of curves, indicating the ability of pluronic $F 127$ to disperse with CLZ and significantly increase in solubility. The solid dispersions of CLZ was carried out with pluronic F127 by different methods and characterized by in vitro drug release, drug content, FTIR, DSC, XRD. All the solid dispersions showed dissolution improvement compare to pure drug. These techniques revealed distinct loss of drug crystallinity in the formulation accounting for enhancement in dissolution rate. The stability study for solid dispersions indicated, all formulations were stable. Methods showing best in vitro drug release profile were selected in further development of mucoadhesive buccal patches. A buccal patch has been developed using mucoadhesive polymers HPMC K4M and carbapol 974. The developed patches were evaluated for the physicochemical, mechanical and drug release characteristics. The optimized patches showed good mechanical and physicochemical properties to withstand environment of oral cavity. The in-vitro permeation study showed that patches could deliver drug to the oral mucosa for a period of $8 \mathrm{hrs}$. The results indicate that suitable bioadhesive buccal patches with good permeability could be prepared. The batches $\mathrm{FH} 4$ and FC4 showed $79.65 \%$ and $79.93 \%$ permeated through goat mucosa membrane in $8 \mathrm{hrs}$. The stability study for buccal patch revealed that all batches were stable.
\end{abstract}

Keywords: Solid dispersions, pluronic F127, chlorzoxazone, dissolution studies, buccal patch.

\section{INTRODUCTION}

The poor solubility of drug (BCS Class II) in gastrointestinal fluid gives rise to variations in dissolution rate and incomplete bioavailability. An improvement of the dissolution rates of water-insoluble drugs is one of the most challenging and important tasks of drug development as it can increase drug bioavailability [1-3]. Chemically, Chlorzoxazone (CLZ) is 5-chloro-3H-benzooxazol-2-one, which belongs to skeletal muscle relaxant (centrally acting) class. It has half life of 1.1 hours \& dose is $250 \mathrm{mg}$. It is soluble in methanol, ethanol \& isopropanol; freely soluble in aq. solutions of alkali hydroxides and slightly soluble in water. It is necessary to improve the dissolution rate of CLZ to enhance the bioavailability [4-5].

There are different chemical or formulation approaches to improve drug dissolution and bioavailability. Among the various strategies solid dispersion technique has often proved to be the most successful in improving the dissolution and bioavailability of poorly soluble drug. There are different methods for preparation of solid dispersion. Solid dispersion is most successful technique as it is simple, economic, and advantageous to enhance dissolution rate [6-13].

*Address correspondence to this author at the Department of Pharmaceutics, MAAER's Maharashtra Institute of Pharmacy, S. No. 124, MIT Campus, Exserviceman Colony, Paud Road, Kothrud, Pune-411038, India; Tel: +919881478118; E-mail: jagdaleswati@rediffmail.com
Buccal delivery of drugs provides an attractive alternate to the oral route of drug administration, particularly in overcoming deficiencies associated with the latter mode of dosing. Problems such as high first pass metabolism and drug degradation in gastrointestinal environment can be circumvented by administering the drug via the buccal route. It is also possible to administer drugs to patients who cannot be dosed orally. Therefore, adhesive mucosal dosage forms were suggested for oral delivery that included adhesive tablets adhesive gels and adhesive patches. However, buccal patches are preferable over adhesive tablets in terms of flexibility and comfort. Now day's bioadhesive polymers received considerable attention as platforms for buccal controlled delivery due to their ability to localize the dosage form in specific regions to enhance drug bioavailability. In order to prepare films having the appropriate characteristics, film-forming polymers were initially used alone and successively in combination with mucoadhesive polymers. The patches with the best characteristics were selected for testing. The plasticizer interposes itself between the polymer chains and interacts with the forces held together by extending and softening the polymer matrix. The commonly used plasticizers include phthalate esters, phosphate esters, fatty acid esters and glycol derivatives [14-19].

The solid dispersion showing best in vitro drug release profile can be selected in further development of buccal patches of CLZ. This would help to facilitate 
its absorption from the buccal cavity, overcome its firstpass metabolism and thereby improve bioavailability.

The purpose of the present investigation was to improve the solubility and dissolution rate of CLZ by forming a solid dispersion with pluronic F127 and to develop buccal mucoadhesive patch to ensure satisfactory CLZ level for prolonged periods. To evaluate performance of the prepared patches and in addition, to investigate the effect of ageing on the performance of the prepared patches.

\section{EXPERIMENTAL}

\subsection{Materials}

Chlorzoxazone was supplied as a gift sample by Twilight Litaka Pharmaceuticals Pvt. Ltd, Pune, India. HPMC K4M and pluronic F127 were gifted from Colorcon Pharmaceuticals (Bangalore, India). Carbapol 974 was gifted by Oxford chemicals (Mumbai, India).

\subsection{Methods}

\section{Drug Characterization}

Melting point of CLZ was determined by melting point apparatus by capillary method to check purity of CLZ.

From the calibration curve of CLZ on UV spectrophotometer (Varian Carry 100, Australia), the wavelength at which maximum absorbance found selected as $\lambda$ max.

\section{Solubility}

CLZ solubility studies were performed in triplicate by adding excess amounts of CLZ to water. The flasks containing solutions were kept on a rotary shaker for 72 hrs then solutions were analyzed using UV spectrophotometer at $\lambda \max$ and concentration was calculated.

\section{Stability in Solvents}

The stability of CLZ was checked by using various solvents like water, phosphate buffer $\mathrm{pH} 6.8,0.1 \mathrm{~N}$ $\mathrm{HCl}$. The CLZ was kept in solvent for $72 \mathrm{hrs}$. The changes in absorbances were noted after a specific period of time.

\section{Infra Red Spectroscopy}

To characterize CLZ, FTIR spectrophotometer (Varian 640 IR, Australia) was employed. The samples were prepared by the $\mathrm{KBr}$ pellet method. The spectra were scanned over a frequency range 4000 to $400 \mathrm{~cm}^{-1}$.

\section{Phase Solubility Studies}

An excess amount of CLZ was added to conical flask containing aqueous solutions of pluronic F127 in increasing concentration $(1 \%, 2 \%, 3 \%, 4 \%$ and $5 \%$ $\mathrm{w} / \mathrm{v})$. The flasks were sealed and shaken at $37 \pm 0.5^{\circ} \mathrm{C}$ for $72 \mathrm{hrs}$ in a mechanical shaker. At equilibrium after $72 \mathrm{hrs}$, aliquots were withdrawn, centrifuged at 4000 rpm for 10 minutes, filtered, diluted suitably and analyzed using by UV spectrophotometer at $280 \mathrm{~nm}$ to determine the solubilities of CLZ at different concentrations of pluronic F127. The experiment was performed in triplicate.

\section{Preparation of Solid Dispersions}

Solid Dispersions were prepared at 1:0.25, 1:0.5, $1: 1,1: 1.5,1: 2,1: 3,1: 5$ ratios, by following methods.

\section{Physical Mixtures (PM)}

The CLZ with pluronic F127 were grinded thoroughly in a mortar, sieved and stored.

\section{Solvent Evaporation Method (SE)}

The CLZ and pluronic F127 were dissolved in methanol separately, sonicated for 20 minutes and then solvent was evaporated under reduced pressure at room temperature in dessicator.

\section{Co-Grinding Method (COG)}

CLZ was triturated in minimum quantity of methanol in mortar until it dissolved. The pluronic F127 was then added and suspension was triturated rapidly at room temperature until the solvent evaporated and passed through sieve and stored.

\section{Co-Precipitation Method (COP)}

An accurately weighed amount of pluronic F127 was dissolved in water and CLZ in methanol, separately. After complete dissolution, the aqueous solution of pluronic $\mathrm{F} 127$ was poured into the methanolic solution of the drug. The solvents were then heated and evaporated under reduced pressure at room temperature in a dessicator.

\section{Kneading Method (KN)}

The mixture of pluronic F127 and CLZ was wetted with water and kneaded thoroughly for 30 minutes in mortar. The paste formed was dried under vacuum for $24 \mathrm{hrs}$, passed through sieve and stored in a dessicator. 


\section{Closed Melting Method (CM)}

PM was transferred into glass ampoules, sealed and heated for $30 \mathrm{~min}$. in water bath. After slow cooling the ampoules were opened and Solid Dispersions werecollected. All solid dispersion were pulverized in mortar, sieved and dried in an oven for at least $48 \mathrm{hrs}$.

\section{Spray Drying Method (SpD)}

The CLZ and pluronic F127 were dissolved in methanol and solution was kept to run from spray drier (Labultima LU 222). The inlet temperature maintained was at $65^{\circ} \mathrm{C}$ and outlet temperature at $40^{\circ} \mathrm{C}$. The aspiration rate was $50-55$. The feed pump speed was $10 \mathrm{ml} / \mathrm{min}$. The cooling temperature was maintained at $35^{\circ} \mathrm{C}$. The powder was collected from collector and stored.

\section{Saturation Solubility Studies}

By equilibrating an excess of CLZ, PM and solid dispersions were placed separately in stoppered conical flasks containing $10 \mathrm{ml}$ distilled water for 48 hours on a mechanical shaker at room temperature. At equilibrium after $48 \mathrm{hrs}$, aliquots were withdrawn, centrifuged at $4000 \mathrm{rpm}$ for 10 minutes, filtered, diluted suitably and analyzed by UV spectrophotometer at 280 $\mathrm{nm}$ to determine CLZ.

\subsection{Characterization of Solid Dispersion}

\section{Percent Drug Content and Yield Study}

The Solid Dispersion equivalent to $250 \mathrm{mg}$ of CLZ was added in $5 \mathrm{ml}$ methanol solution kept in ultra sonicator for $10 \mathrm{~min}$., volume was adjusted to $100 \mathrm{ml}$ with distilled water. The solution was filtered, suitably diluted and assayed using UV spectrophotometer at $280 \mathrm{~nm}$. The CLZ content was calculated using calibration curve. The Solid Dispersion were weighed and yield was calculated for each preparation using following formula

$\%$ Yield $=(a / b) \times 100$

eqn. 1

Where, ' $a$ ' is the practical weight of solid dispersion obtained and ' $b$ ' is the theoretical weight of solid dispersion.

\section{In Vitro Release Study}

In vitro release studies of CLZ from solid dispersion (equivalent with $250 \mathrm{mg}$ ) were studied in $900 \mathrm{ml}$ distilled water as dissolution medium, at $37 \pm 0.5^{\circ} \mathrm{C}$ and 75 rpm, using USP I dissolution test apparatus (basket type) (TDT-08L Electrolab, Mumbai, India). Aliquots were withdrawn, at the specified time interval and replenished immediately with same volume of fresh medium. Aliquots were filtered, diluted suitably and assayed for CLZ using UV spectrophotometer at 280 $\mathrm{nm}$. Dissolution profiles of the formulations were analyzed by plotting time versus \% drug release. The whole study was also performed with phosphate buffer (pH 6.8) as a dissolution medium with all other same parameters. The dissolution experiment was performed in triplicate for each sample.

\section{Fourier Transform Infrared Spectroscopy Study (FTIR)}

The spectra of CLZ, pluronic F127 and solid dispersions were recorded with FTIR spectrophotometer using $\mathrm{KBr}$ disks. The spectra were comparatively analyzed for drug-carrier interaction. The scanning range used was 4000 to $500 \mathrm{~cm}^{-1}$.

\section{Powder X-Ray Diffraction Study (PXRD)}

XRD (Philips PW 1729, Netherlands) was employed for tracing XRD patterns of CLZ and Solid Dispersions, using $\mathrm{Ni}$ filter, CuK $(\alpha)$ radiation, a voltage of $\mathrm{kV}$, a current of $20 \mathrm{~mA}$ and receiving slit of $0.2 \mathrm{in}$. The samples were analyzed over $2 \theta$ range of $5^{\circ}$ to $50^{\circ}$, with scan step size of $0.020^{\circ}(2 \theta)$ and scan step time of 1 second.

\section{Differential Scanning Calorimetry Study (DSC)}

DSC (Lab Mettler Star ${ }^{\mathrm{e}}$ SW 9.20, Switzerland) was used to obtain the curves of CLZ, pluronic F127 and solid dispersions representing the rates of heat uptake. About $2-5 \mathrm{mg}$ of sample was weighed in a standard open aluminum pans, were scanned from $40-250^{\circ} \mathrm{C}$, at a heating rate of $10^{\circ} \mathrm{C} / \mathrm{min}$ while being purged with dry nitrogen. The instrument was calibrated prior to sample analysis, using an indium standard.

\section{Stability Study of Solid Dispersions}

The selected solid dispersions were packed in amber- colored bottles, which were tightly plugged with cotton and capped with aluminum. They were stored at $25^{\circ} \mathrm{C} / 60 \%$ Relative Humidity $(\mathrm{RH}), 30^{\circ} \mathrm{C} / 65 \% \mathrm{RH}, \&$ $40^{\circ} \mathrm{C} / 75 \% \mathrm{RH}$ for 3 months and evaluated for their physical changes such as color and texture, drugpolymer interaction using FTIR, drug content and In vitro drug release study.

\subsection{Formulation of Buccal Patches}

Solid dispersion showing high solubility was selected for development of mucoadhesive buccal 
Table 1: Composition of CLZ Mucoadhesive Buccal Patch

\begin{tabular}{|c|c|c|c|c|c|c|c|c|c|c|c|c|c|c|}
\hline \multirow[t]{2}{*}{ Component } & \multicolumn{14}{|c|}{ Formulation batch code } \\
\hline & FH 1 & FH 2 & FH 3 & FH 4 & FH 5 & FH 6 & FH 7 & FC 1 & FC 2 & FC 3 & FC 4 & FC 5 & FC 6 & FC 7 \\
\hline $\begin{array}{c}\text { Solid dispersion equivalent } \\
\text { to CLZ (mg) }\end{array}$ & 250 & 250 & 250 & 250 & 250 & 250 & 250 & 250 & 250 & 250 & 250 & 250 & 250 & 250 \\
\hline HPMC K4M (\%) & 1 & 1.5 & 2 & 2.5 & 3 & 3.5 & 4 & - & - & - & - & - & - & - \\
\hline Carbapol 974 (\%) & - & - & - & - & - & - & - & 2 & 2.5 & 3 & 3.5 & 4 & 4.5 & 5 \\
\hline Propylene glycol (\%) & 10 & 10 & 10 & 10 & 10 & 10 & 10 & 13 & 13 & 13 & 13 & 13 & 13 & 13 \\
\hline
\end{tabular}

patches. The formulation of buccal patch (Table 1) is carried out by using two different water swellable polymers hydroxy propyl methyl cellulose (HPMC K4M) and carbapol 974 . The plasticizer used was propylene glycol. The patch consists of solid dispersion (equivalent to $250 \mathrm{mg}$ of $\mathrm{CLZ}$ ). All patches were prepared by solvent casting method [16].

The variables used while formulating the patch were concentrations of HPMC K4M, carbapol 974 and plasticizer (propylene glycol). The concentration of HPMC K4M was varied from $1 \%$ to $4 \%$ and for carbapol 974 was varied from $2 \%$ to $5 \%$. The concentration of plasticizer was finalized differently for the two polymers from the plasticity of the film. It is varied from $10 \%$ to $15 \%$ for the patch.

\section{Tissue Preparation}

The goat esophageal tissue was obtained immediately post-sacrifice from a local slaughterhouse (Kothrud, Pune). It is transported to the laboratory in isotonic phosphate buffer $(\mathrm{pH} 7.4)$ and opened longitudinally and rinsed with same. The mucosa was removed from the underlying muscular layer by cutting the loose connective fibers with a scalpel. Circular pieces were then punched out. The excised mucosa was immersed in isotonic saline at $60^{\circ} \mathrm{C}$ for $1 \mathrm{~min}$ then the epithelium was peeled away from connective tissue.

\subsection{Evaluation}

\section{Evaluation of Buccal Patch}

Randomly five patches of $10 \mathrm{~mm}$ size $\left(1 \times 1 \mathrm{~cm}^{2}\right)$ were selected from every batch for every test and a mean of five readings were recorded.

\section{Patch Thickness and Mass}

The thickness was determined using a standard micrometer screw gauge and weight uniformity was determined by weighing on electronic balance.

\section{Surface $p H$}

Agar plate, prepared by dissolving $2 \%(\mathrm{w} / \mathrm{v})$ agar in warmed isotonic phosphate buffer $(\mathrm{pH}$ 7.4) under stirring and then pouring the solution in a petri dish and cooling till gelling at room temperature. The patches were left to swell for $2 \mathrm{hrs}$ on the surface of agar plates then $\mathrm{pH}$ was measured with $\mathrm{pH}$ paper placed on the surface of the swollen patch.

\section{Folding Endurance Test}

This test was done by repeatedly folding the patch at the same place up to maximum 200 times or till it broke.

\section{Swelling Index}

The weight and diameter of original patches were determined, placed on the surface of $2 \%$ agar gel plate kept in an incubator maintained at $37 \pm 0.5^{\circ} \mathrm{C}$. After the preset time interval $(1 \mathrm{hr})$ the patches were removed from the petri dish and excess surface water was removed carefully using the filter paper. Then swollen patches were reweighed and the swelling index was calculated. The measurements of diameters of patches were done by using microscope after one hour interval for $5 \mathrm{hrs}$. The percentage swelling (\%S) was calculated using the following equation:

$\% \mathrm{~S}=\left(\mathrm{Wt}-\mathrm{W}_{0} / \mathrm{W}_{0}\right)^{*} 100$

eqn. 2

$\mathrm{Wt}$ is weight of the patch after time $t$ and $\mathrm{W}_{0}$ is the initial weight at zero time.

\section{Vapour Transmission Test (VTR)}

The glass-bottle (length $=5 \mathrm{~cm}$, narrow mouth with internal diameter $=0.8 \mathrm{~cm}$ ) filled with $2 \mathrm{gm}$ anhydrous calcium chloride and an adhesive (Feviquick) spread across its rim, was used in the study. The patch was fixed over the adhesive and the assembly was placed in a constant humidity chamber, prepared using saturated solution of ammonium chloride and maintained at $37 \pm 2^{\circ} \mathrm{C}$. The difference in weight after 24 
h, 3rd day and 1 week was calculated. The vapor transmission rate was obtained as follow:

VTR $=$ (Amount of moisture transmitted) $/$ (Area $x$ Time) eqn. 3

\section{In-Vitro Mucoadhesive Strength}

The strength of bond formed between the patch and mucosa membrane excised from goat mucosa was determined using two-arm balance method. Fresh goat mucosa section was fixed on the plane surface of glass slide $(3 \times 5 \mathrm{~cm})$ attached (with adhesive tape) to bottom of smaller beaker, kept inverted in $500 \mathrm{ml}$ beaker attached to the bigger beaker. Isotonic phosphate buffer ( $\mathrm{pH}$ 6.8) was added to the beaker up to the upper surface inverted beaker with goat mucosa. The patch was stuck to the lower side of the upper clamp with cyanoacrylate adhesive. The exposed patch surface was moistened with phosphate buffer $(\mathrm{pH} 6.8)$ and left for 30s for initial hydration and swelling. Then the platform was slowly raised until the patch surface came in contact with mucosa. Two sides of the balance were made equal before study. After a preload (50 gm) time of 2 minutes, water was added to the polypropylene bottle present in another arm, until the patch was detached from the mucosa. The water collected in the bottle was measured and expressed as weight $(\mathrm{gm})$ required for the detachment. The force measurement was repeated 3 times for each formulation. The following parameters were calculated from the bioadhesive strength:

Force of adhesion $(\mathrm{N})=($ Bioadhesive strength $(\mathrm{gm})$ * 9.81) / 1000 eqn. 4

Bond strength $\left(\mathrm{Nm}^{2}\right)=$ Force of adhesion / Disk surface area eqn. 5

\section{In-Vitro Residence Time}

It was evaluated after application of the patches onto freshly cut goat mucosa. The fresh goat mucosa was fixed in the inner side of the beaker, above $2.5 \mathrm{~cm}$ from the bottom, with cyanoacrylate glue. One side of each patch was wetted with one drop of phosphate buffer ( $\mathrm{pH}$ 6.8) and pasted to the goat mucosa by applying a light force with a fingertip for 30 seconds. The beaker was filled with $500 \mathrm{~mL}$ of isotonic phosphate buffer $(\mathrm{pH} 6.8)$ and was kept at $37 \pm 1^{\circ} \mathrm{C}$. After 2 minutes, a $50 \mathrm{rpm}$ stirring rate was applied to simulate the buccal cavity environment, and patch adhesion was monitored up to $8 \mathrm{hrs}$. The time required for the patch to detach from the mucosa was recorded as the mucoadhesion time.

\section{Content Uniformity}

The buccal patch $\left(1 \times 1 \mathrm{~cm}^{2}\right)$ was dissolved in $100 \mathrm{ml}$ of phosphate buffer ( $\mathrm{pH}$ 6.8) for 6 hrs under occasional shaking. The $5 \mathrm{ml}$ solution was withdrawn, filtered, diluted with same medium upto $20 \mathrm{ml}$ and CLZ content was determined by using a UV-spectrophotometer at $280 \mathrm{~nm}$.

\section{In-Vitro Release Study}

The release study was done in the Keshery-Chien diffusion cell using phosphate buffer $(\mathrm{pH}$ 6.8). The membrane was carefully mounted in between the compartments of a diffusion cell. The receptor and donor compartment contained $12 \mathrm{ml}$ and $3 \mathrm{ml}$ of phosphate buffer ( $\mathrm{pH} 6.8)$, respectively. The entire set up was placed over magnetic stirrer and temperature was maintained at $37 \pm 2^{\circ} \mathrm{C}$. Aliquots $(1 \mathrm{ml})$ were collected from receptor compartment at predetermined time interval upto $8 \mathrm{hrs}$ and replaced with equal volumes of fresh medium kept at the same temperature. Aliquots were filtered, diluted suitably with same medium and assayed for CLZ using UV spectrophotometer at $280 \mathrm{~nm}$. The diffusion profiles of the formulations were analyzed by plotting time versus $\%$ drug release. The membranes used for diffusion study was celophan for all batches. Then for optimized batches, egg membrane and goat mucosa were used and the study was repeated in triplicate with each membrane.

\section{FTIR Study of Buccal Patches}

The samples of CLZ with HPMC K4M and with carbapol 974 were prepared by simple blending with $\mathrm{KBr}$. The scanning range used was 4000 to $500 \mathrm{~cm}^{-1}$. Then the spectra were comparatively analyzed for drug-carrier interaction.

\section{Stability Study of Buccal Patches}

The stability study was carried out for optimized batches of formulated buccal patch. The selected patches were packed in aluminum then in ambercolored bottles, which were tightly plugged with cotton and capped with aluminum. They were stored at $25^{\circ} \mathrm{C} / 60 \% \mathrm{RH}, 30^{\circ} \mathrm{C} / 65 \% \mathrm{RH}, \& 40^{\circ} \mathrm{C} / 75 \% \mathrm{RH}$ for 3 months and evaluated for their physical changes such as color and texture, drug-polymer interaction, drug content and in vitro drug release study after 1, 2, 3 months.

\section{RESULTS \& DISCUSSION}

\subsection{Drug Characterization}

Melting point of CLZ was found in the range of $191^{\circ} \mathrm{C}-192^{\circ} \mathrm{C}$. 


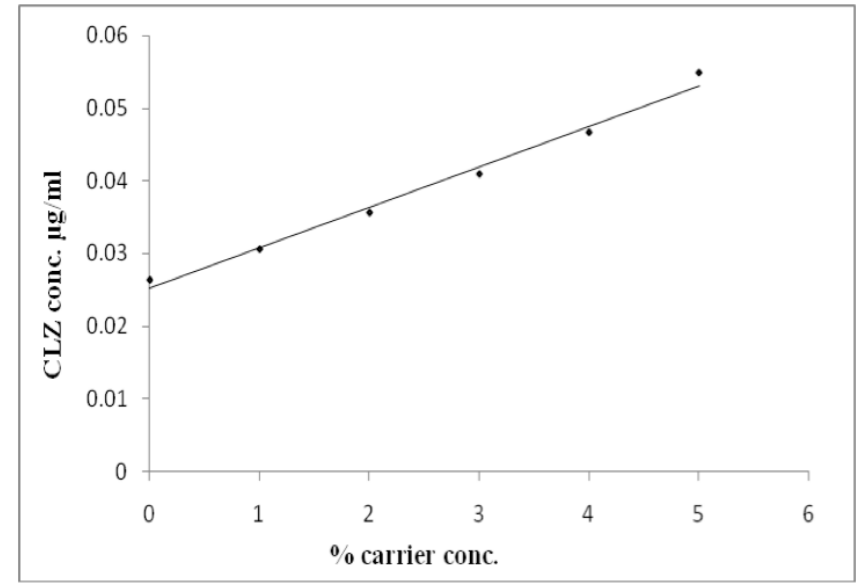

Figure 1: Phase solubility study of CLZ $(\mu \mathrm{g} / \mathrm{ml})$ with pluronic F127 in water.

The maximum absorbance of CLZ found at $280 \mathrm{~nm}$. So, $\lambda \max$ of CLZ selected at $280 \mathrm{~nm}$.

\section{Solubility}

Solubility of CLZ in water was found to be $25.58 \mu \mathrm{g} / \mathrm{ml}$ indicating it is slightly soluble in water.

\section{Stability in Solvents}

There were no major changes in absorbances observed. It indicated that CLZ was stable in solvents water, phosphate buffer $\mathrm{pH} 6.8,0.1 \mathrm{~N} \mathrm{HCl}$.

\section{Infra Red Spectroscopy}

The FTIR spectra analysis of CLZ showed, the characteristic peaks for specific structural groups were observed at wave numbers $3587.98,3221.36,3066.96$, 2901.12, 1765.57, 1623.81, 1582.71, 1356.98, 850.02, $766.25 \mathrm{~cm}^{-1}$ confirming the purity of drug as per established standards.

\subsection{Phase Solubility Study}

This study show that the curve (Figure 1) obtained are $A_{L}$ type because of linear increase in solubility with the value of $R^{2}$ closed to unity. The solubility parameters of CLZ at $25^{\circ} \mathrm{C}$ when carrier is pluronic $\mathrm{F} 127$ is used, the slope was 0.04765 , stability constant (Ks) was 89.12, value of $R^{2}$ was 0.9984 and Gibb's free energy of transfer $\left(\Delta \mathrm{G}_{\mathrm{tr}}{ }^{0}\right)$ was -29.42 joules $/ \mathrm{mol}$. The negative sign of Gibb's free energy of transfer indicates the spontaneous nature of CLZ solubilization.

The results of saturation solubility study (Table 2) indicated that maximum increase in solubility in ratio 1:1. The co-precipitation method showed maximum saturation solubility.

\section{Percent Practical Yield \& Drug Content}

The practical yield was in the range of $94.05 \pm$ $3.02 \%$ to $99.13 \pm 1.76 \%$ and drug content ranged between $95.68 \pm 3.11 \%$ and $99.55 \pm 1.84$ (Table 3). The results indicate that processes employed to prepare Solid Dispersion in this study were capable of producing formulation with uniform drug content.

\section{In Vitro Release Study}

The in-vitro release of solid dispersions showed a significant increase in drug release, in comparison with pure crystalline CLZ in both dissolution medium (Figure 2, 3). Among different methods, the maximum of dissolution enhancement was found with kneading method. The order of dissolution enhancement by solid dispersion is $\mathrm{COP}>\mathrm{KN}>\mathrm{COG}>\mathrm{SpD}>\mathrm{PM}>\mathrm{SE}>$ CM.

\section{Fourier Transform Infrared Spectroscopy (FTIR)}

The IR spectra of solid dispersion (Figure 4) showed some additional peaks were observed, which could be due to the presence of pluronic F127. While all other characteristic peaks of CLZ are at the same wave number. This indicated that no interactions of CLZ with pluronic F127.

Table 2: Saturation Solubility of CLZ with Pluronic F127

\begin{tabular}{|c|c|c|c|c|c|c|}
\hline \multirow[t]{2}{*}{ Sr. No. } & \multirow[t]{2}{*}{ Preparation Methods } & \multicolumn{5}{|c|}{ Saturation Solubility on Various Ratio of pluronic F127 $(\mu \mathrm{g} / \mathrm{ml})$} \\
\hline & & $1: 1$ & $1: 3$ & 1:5 & $1: 2$ & 1:0.5 \\
\hline 1 & Physical mixture (PM) & 136.93 & 89.77 & 78.39 & 103.27 & 98.47 \\
\hline 2 & Solvent evaporation (SE) & 126.42 & 81.06 & 70.51 & 88.49 & 103.39 \\
\hline 3 & Co-Grinding (COG) & 149.98 & 78.53 & 71.09 & 80.13 & 87.46 \\
\hline 4 & Co precipitation (COP) & 215.64 & 83.15 & 74.88 & 84.76 & 112.37 \\
\hline 5 & Kneading $(\mathrm{KN})$ & 185.26 & 125.38 & 98.54 & 118.35 & 146.0 \\
\hline 6 & Closed Melting $(\mathrm{CM})$ & 125.05 & 71.26 & 67.28 & 94.22 & 82.29 \\
\hline 7 & Spray Drying (SpD) & 123.87 & 79.58 & 72.29 & 90.67 & 98.23 \\
\hline
\end{tabular}


Table 3: Percent Practical Yield \& Drug Content of Solid Dispersions of CLZ with Pluronic F127 (1:1)

\begin{tabular}{|c|c|c|c|}
\hline Sr. No. & Preparation methods & Practical yield \pm SD (\%) & $97.44 \pm 2.18$ \\
\hline \hline 1 & Physical mixture (PM) & $98.52 \pm 1.69$ & $98.29 \pm 1.94$ \\
\hline 2 & Solvent evaporation (SE) & $96.78 \pm 2.51$ & 97.11 \\
\hline 3 & Co-Grinding (COG) & $98.49 \pm 2.63$ & $99.55 \pm 1.84$ \\
\hline 4 & Co precipitation (COP) & $99.13 \pm 1.76$ & $98.74 \pm 1.97$ \\
\hline 5 & Kneading (KN) & $95.78 \pm 2.41$ & $97.25 \pm 2.25$ \\
\hline 6 & Closed Melting (CM) & $94.05 \pm 3.02$ & $96.82 \pm 2.36$ \\
\hline
\end{tabular}

*Average of three determinations, $\pm S D$ - Standard deviation $n=3$.

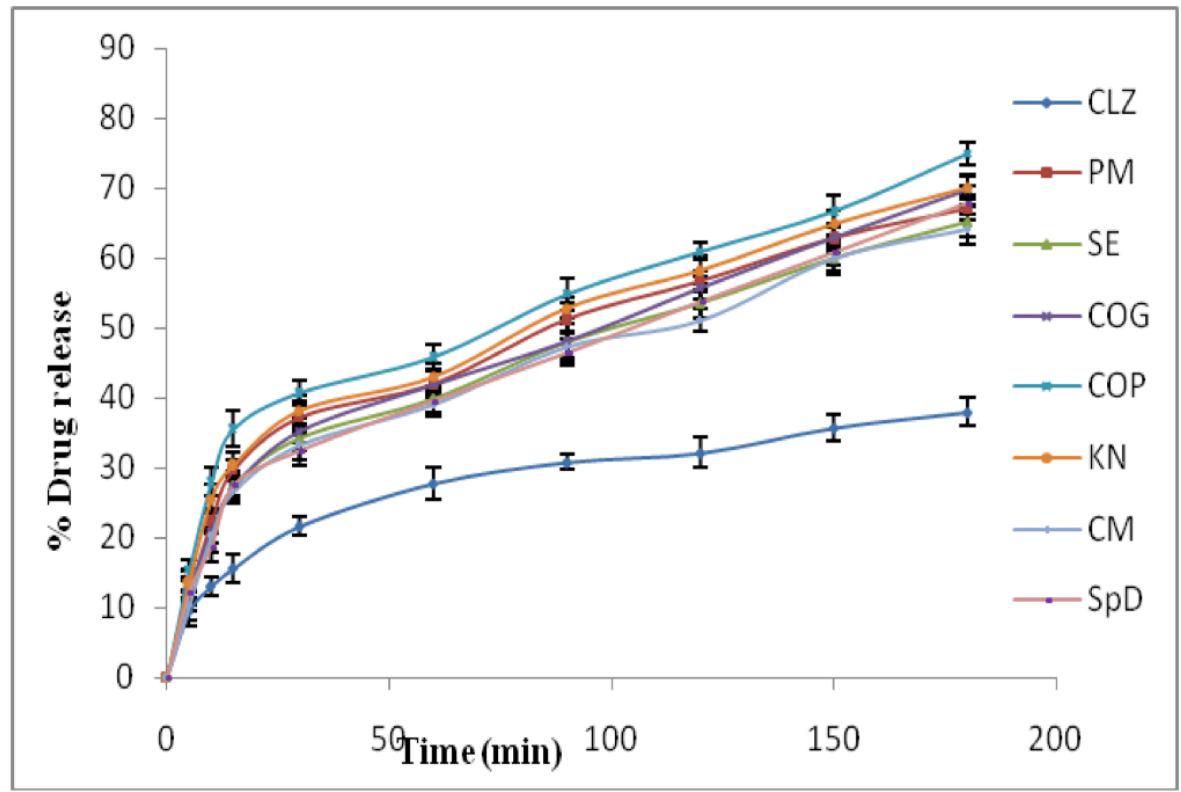

Figure 2: Release profile of all solid dispersions in distilled water.

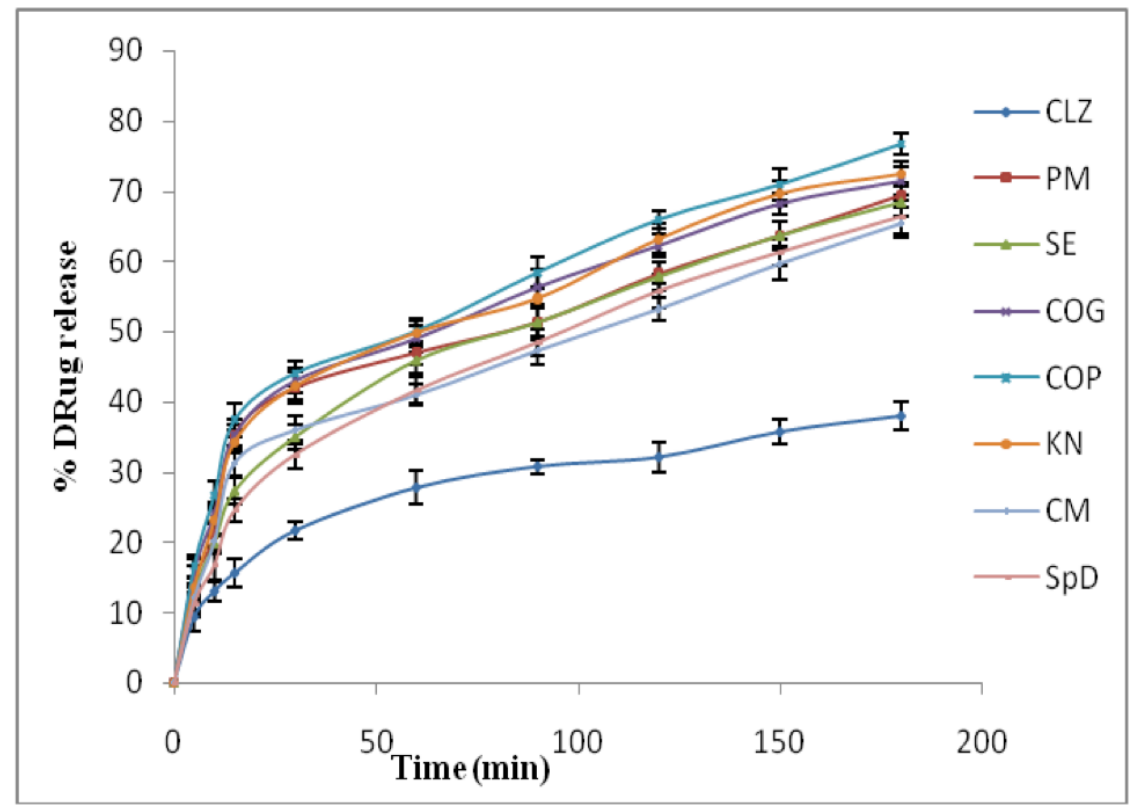

Figure 3: Release profile of all solid dispersions in phosphate buffer ( $\mathrm{pH} 6.8)$. 


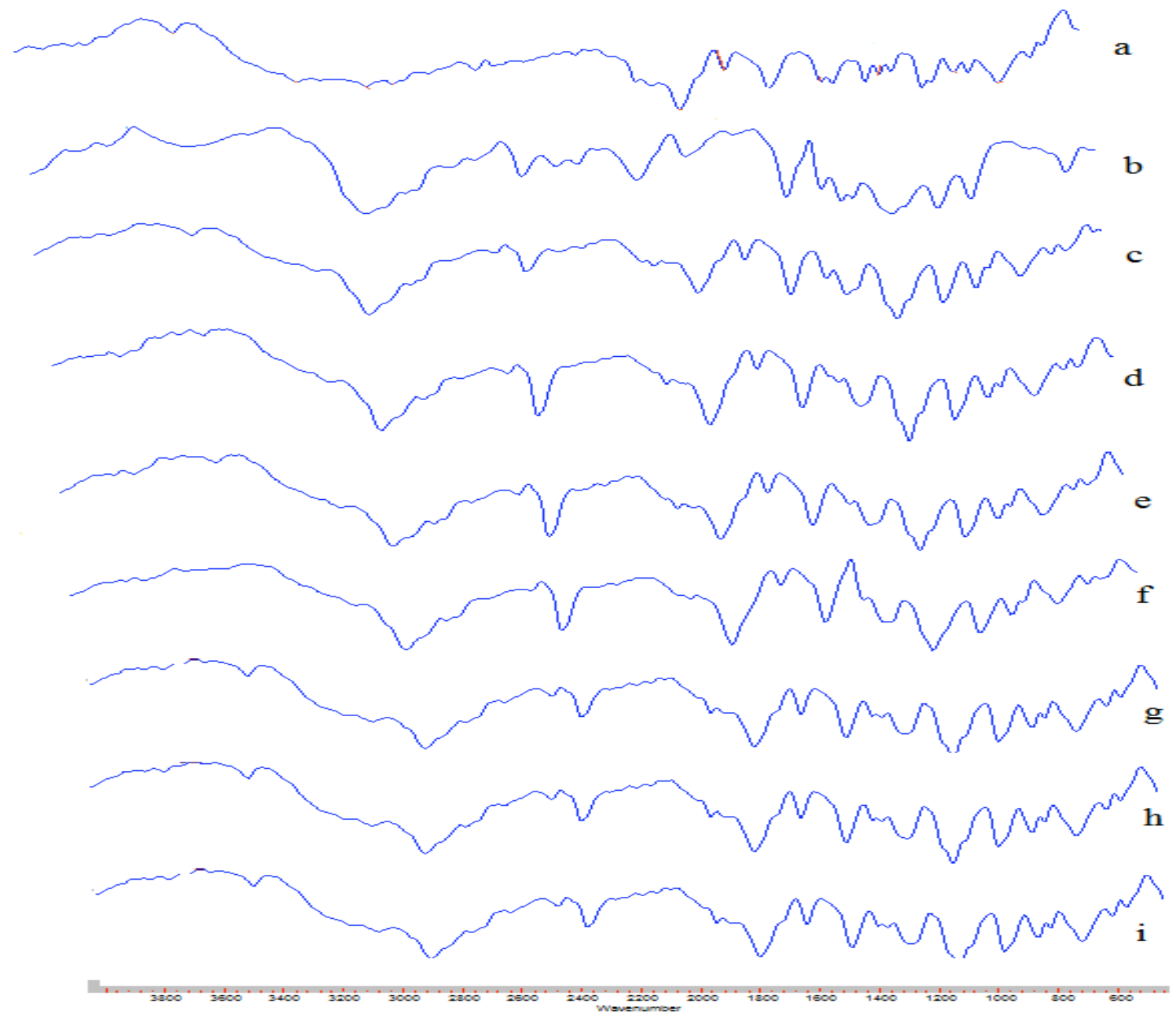

Figure 4: FTIR spectra of: a- CLZ, b- pluronic F127, c- PM, d- KN, e- COG, f- COP, g- SE, h- CM and i- SpD.

\section{Powder X-Ray Diffractometry (PXRD)}

PXRD pattern of CLZ (Figure 5) showed its highly crystalline nature, as indicated by the numerous distinctive peaks at $2 \theta$ values are $10.6,11.5,12.1$, $12.8,13.2,13.8,15.5,16.3,17.8,19.9,21.1,21.6$, $25.2,25.8,27.5,28.1,29.4,30.3$ and 32.1. The lack of the numerous distinctive peaks of CLZ in XRD pattern Solid Dispersion of COP, KN and COG (Figure 5) demonstrated that a high concentration of CLZ was dissolved in carrier matrix in an amorphous state.

\section{Differential Scanning Calorimetry (DSC)}

In DSC curve of CLZ and pluronic F127 (Figure 6) sharp endothermic peaks were observed at $191.16^{\circ} \mathrm{C}$ and $58.7^{\circ} \mathrm{C}$, respectively. It is due to fusion, corresponding to its melting point. DSC curve of solid dispersions $\mathrm{COP}, \mathrm{KN}$ and $\mathrm{COG}$ (Figure 6) showed position of endothermic peak of is shifted at $44.97^{\circ} \mathrm{C}$, $48.14^{\circ} \mathrm{C}, 49.03^{\circ} \mathrm{C}$, respectively and intensity of peak is reduced. It indicates melting of CLZ becomes faster and it might be due to the amorphous form of CLZ in solid dispersion or dissolution of crystalline CLZ into the molten carrier.

\section{Stability Study of Solid Dispersion}

The stability study was carried out for solid dispersion prepared by COP, KN and COG methods and parameters for study were drug content, in vitro release studies and FTIR. These studies conclude that there was no degradation. Hence, these Solid Dispersions can be kept for a period of one year or more with respect to time.

\subsection{Buccal Patch}

The concentrations of polymers were decided by varying the concentration. The patches prepared other than optimized concentration showed some problem with their physicochemical properties like no flexibility, no drying, hard, brittle, entrapment of air bubble, stickiness etc. The patches showing good results were selected. 

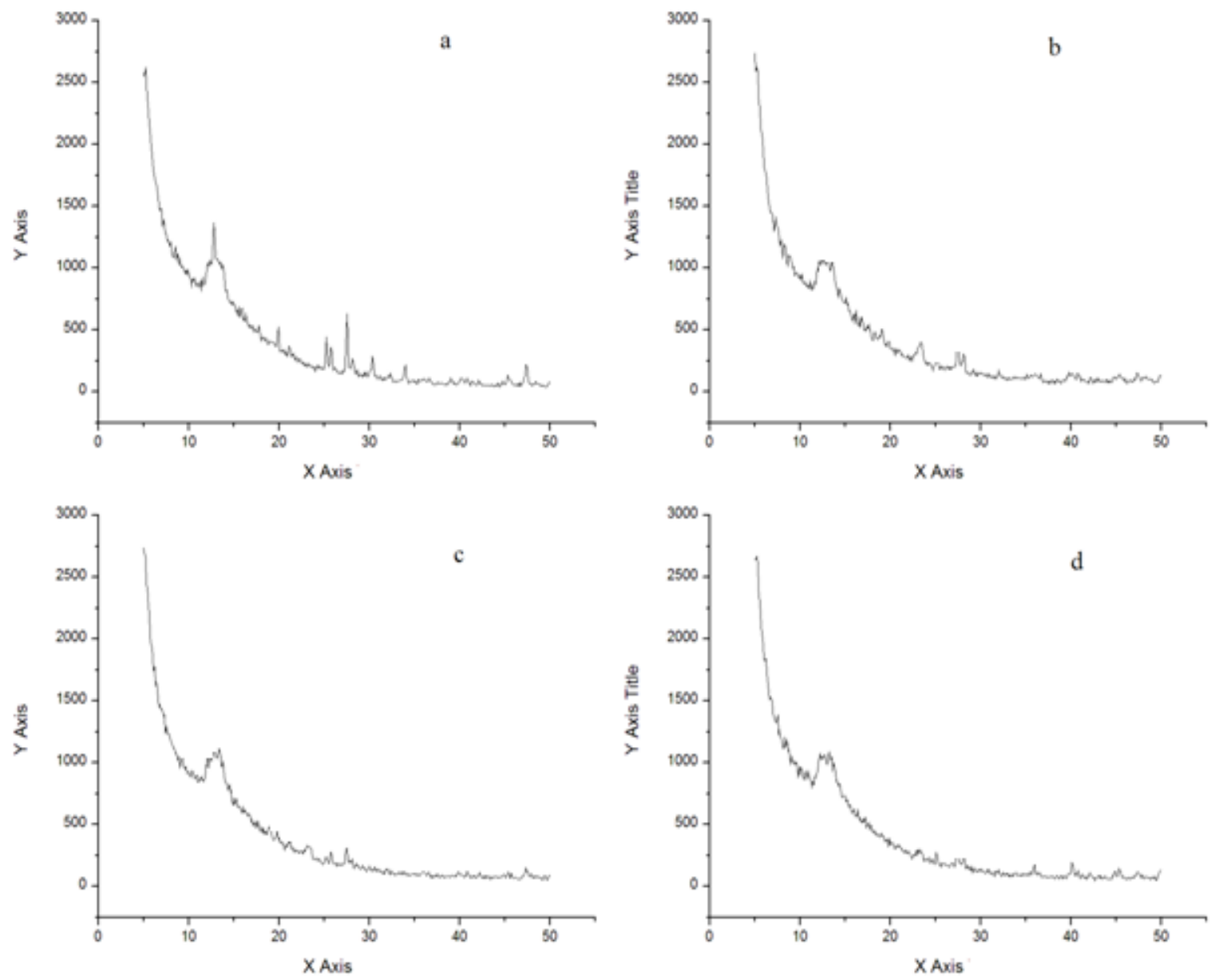

Figure 5: PXRD pattern of: a- CLZ, b-COP, c- KN and d- COG.

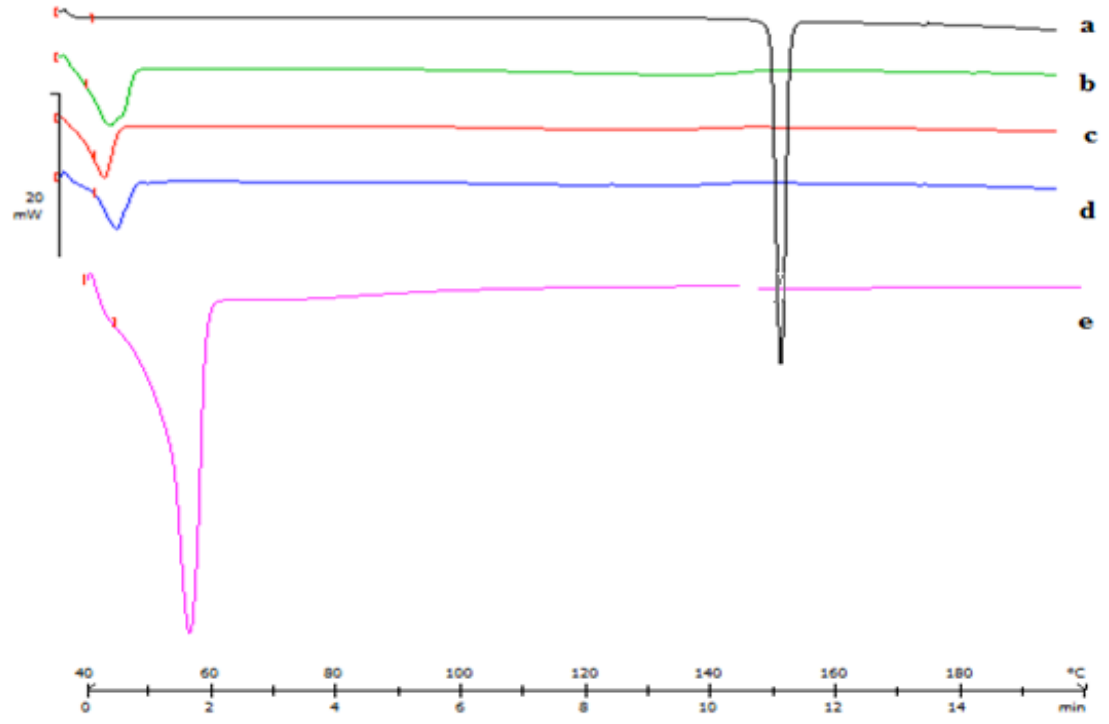

Figure 6: DSC curves of: a- CLZ, b- COP, c- KN, d- COG and e- pluronic F127.

The concentration of HPMC K4M and carbapol 974 were finalized as $2.5 \%$ and $3.5 \%$ respectively, as it showed good results. The concentration of plasticizer was finalized differently for the two polymers from the 
plasticity of the film. It is $10 \%$ and $13 \%$ for the patch of HPMC K4M and carbapol 974, respectively.

In comparison to pure drug, solid dispersion prepared by co-precipitation method showed maximum release profile among all solid dispersions. So, it was selected for further patch formulation study as it. The solid dispersion equivalent to $250 \mathrm{mg}$ of CLZ was weighed accurately and incorporated in a buccal patch.

The physical characteristics of all patches are shown in Table 3. All the patches were $10 \mathrm{~mm}$ in diameter. The thickness and mass of all formulations were in the range of $0.63 \pm 0.28$ to $1.19 \pm 0.52$ and $27.13 \pm 0.58$ to $425.27 \pm 0.38$, respectively.

The surface $\mathrm{pH}$ within the desirable 6-7 units which were near to neutral $\mathrm{pH}$ and hence no mucosal irritation would be expected (Table 4).

The folding endurance recorded for all patches were more than 200. This might be due to adequate content of propylene glycol, provides high mechanical strength and good elasticity.

Assessment of the swelling behavior was done by measuring radial swelling. The medicated patches showed higher radial swelling compared to placebo patches. The swelling index after 5 hrs was in the range of $34.96 \pm 2.81$ to $65.43 \pm 3.91$. Higher swelling index would result in excessively increased surface area which could result in unmanageable faster release of the drug and also may cause patient discomfort due to occupying of larger space in the oral cavity and chances of dislodgement.

In vapour transmission, the formulation batches FH1, FH3, FC1, FC2, FC5 were indicate less vapour transmission as compared to other batches on day seven. The highest vapour permeation 1.67 $\times 10^{-3} \pm 0.13 \times 10^{-3} \mathrm{gcm}^{-2} \mathrm{~h}^{-1}$ was found with batch FC7 on day seven. While less permeation $0.68 \times 10^{-3} \pm$ $0.37 \times 10^{-3} \mathrm{gcm}^{-2} \mathrm{~h}^{-1}$ was found on day seven with patch FH3 (Table 5).

The in vitro residence time was found in the range of $2.54 \pm 0.82$ to $3.73 \pm 0.88 \mathrm{hrs}$.

The drug content in the patches was found in the range of $96.18 \pm 0.27 \%$ and $101.98 \pm 0.44 \%$.

The optimized batches $\mathrm{FH} 4$ and FC4 showed $85.92 \%$ and $86.26 \%$ CLZ release, respectively from celophan membrane. From egg membrane, 83.28\% and $82.36 \%$ and from goat mucosa, $79.65 \%$ and 79.93\% CLZ released, respectively for $\mathrm{FH} 4$ and FC4. All the release profile follows peppas model. The

Table 4: Physicochemical Characteristics of Buccal Patches

\begin{tabular}{|c|c|c|c|c|}
\hline Formulation code & Thickness \pm SD $^{\star}(\mathrm{mm})$ & Mass \pm SD $^{*}(\mathrm{mg})$ & Surface $\mathrm{pH} \pm \mathrm{SD}^{*}$ & $\begin{array}{c}\text { Swelling index after } 5 \\
\text { hrs } \pm S D^{\star}\end{array}$ \\
\hline Placebo H & $0.65 \pm 0.24$ & $27.13 \pm 0.58$ & $6.09 \pm 0.135$ & $34.96 \pm 2.81$ \\
\hline $\mathrm{FH} 1$ & $0.78 \pm 0.19$ & $421.78 \pm 0.72$ & $6.57 \pm 0.08$ & $50.18 \pm 4.86$ \\
\hline $\mathrm{FH} 2$ & $0.87 \pm 0.41$ & $419.45 \pm 0.44$ & $6.41 \pm 0.47$ & $54.38 \pm 5.43$ \\
\hline $\mathrm{FH} 3$ & $0.84 \pm 0.09$ & $420.19 \pm 0.25$ & $5.94 \pm 0.93$ & $53.15 \pm 2.45$ \\
\hline $\mathrm{FH} 4$ & $0.96 \pm 0.53$ & $417.83 \pm 0.91$ & $6.11 \pm 0.67$ & $62.47 \pm 4.31$ \\
\hline FH5 & $1.04 \pm 0.81$ & $418.02 \pm 0.82$ & $6.76 \pm 0.078$ & 59. $24 \pm 6.75$ \\
\hline $\mathrm{FH} 6$ & $1.13 \pm 0.57$ & $419.46 \pm 0.41$ & $6.27 \pm 0.12$ & $63.17 \pm 4.69$ \\
\hline $\mathrm{FH} 7$ & $1.18 \pm 0.26$ & $424.18 \pm 0.76$ & $7.01 \pm 0.091$ & $44.41 \pm 5.72$ \\
\hline Placebo C & $0.63 \pm 0.28$ & $25.64 \pm 0.54$ & $5.89 \pm 0.67$ & $37.54 \pm 1.90$ \\
\hline FC1 & $0.75 \pm 0.68$ & $419.37 \pm 0.13$ & $6.73 \pm 0.73$ & $46.48 \pm 3.81$ \\
\hline FC2 & $0.86 \pm 0.26$ & $419.93 \pm 0.33$ & $6.01 \pm 0.84$ & $61.89 \pm 6.52$ \\
\hline FC3 & $0.88 \pm 0.08$ & $421.72 \pm 0.39$ & $6.78 \pm 0.065$ & $55.56 \pm 5.68$ \\
\hline FC4 & $0.94 \pm 0.15$ & $422.48 \pm 0.67$ & $5.35 \pm 0.44$ & $52.69 \pm 4.51$ \\
\hline FC5 & $0.98 \pm 0.77$ & $421.25 \pm 0.43$ & $6.42 \pm 0.095$ & $54.88 \pm 6.53$ \\
\hline FC6 & $1.12 \pm 0.39$ & $423.33 \pm 0.61$ & $5.75 \pm 0.17$ & $65.43 \pm 3.91$ \\
\hline FC7 & $1.19 \pm 0.52$ & $425.27 \pm 0.38$ & $6.31 \pm 0.25$ & $56.51 \pm 5.23$ \\
\hline
\end{tabular}

*Average of three determinations, $\pm S D$ - Standard deviation $n=3$. 
Table 5: Vapour Transmission Rate through the Buccal Patches

\begin{tabular}{|c|c|c|c|}
\hline \multirow{2}{*}{$\begin{array}{c}\text { Formulation } \\
\text { code }\end{array}$} & \multicolumn{3}{|c|}{ Moisture Vapour Transmission \pm SD $^{*}\left(\mathrm{gcm}^{-2} \mathbf{h}^{-1}\right)$} \\
\hline \hline Placebo H & $8.68 \times 10^{-3} \pm 1.41 \times 10^{-3}$ & Day 3 & Day 7 \\
\hline FH1 & $5.39 \times 10^{-3} \pm 1.45 \times 10^{-3}$ & $4.05 \times 10^{-3} \pm 0.97 \times 10^{-3}$ & $0.86 \times 10^{-3} \pm 0.81 \times 10^{-3}$ \\
\hline FH2 & $7.53 \times 10^{-3} \pm 2.26 \times 10^{-3}$ & $2.68 \times 10^{-3} \pm 0.59 \times 10^{-3}$ & $1.51 \times 10^{-3} \pm 0.04 \times 10^{-3}$ \\
\hline FH3 & $7.75 \times 10^{-3} \pm 1.78 \times 10^{-3}$ & $2.97 \times 10^{-3} \pm 0.87 \times 10^{-3}$ & $0.68 \times 10^{-3} \pm 0.37 \times 10^{-3}$ \\
\hline FH4 & $6.97 \times 10^{-3} \pm 2.04 \times 10^{-3}$ & $2.64 \times 10^{-3} \pm 0.16 \times 10^{-3}$ & $0.97 \times 10^{-3} \pm 0.81 \times 10^{-3}$ \\
\hline FH5 & $7.46 \times 10^{-3} \pm 2 . .64 \times 10^{-3}$ & $3.53 \times 10^{-3} \pm 0.48 \times 10^{-3}$ & $1.62 \times 10^{-3} \pm 0.59 \times 10^{-3}$ \\
\hline FH6 & $6.96 \times 10^{-3} \pm 1.12 \times 10^{-3}$ & $2.87 \times 10^{-3} \pm 0.13 \times 10^{-3}$ & $1.08 \times 10^{-3} \pm 0.39 \times 10^{-3}$ \\
\hline FH7 & $3.68 \times 10^{-3} \pm 2.48 \times 10^{-3}$ & $2.15 \times 10^{-3} \pm 0.75 \times 10^{-3}$ & $1.35 \times 10^{-3} \pm 0.75 \times 10^{-3}$ \\
\hline Placebo C & $9.67 \times 10^{-3} \pm .64 \times 10^{-3}$ & $1.75 \times 10^{-3} \pm 0.64 \times 10^{-3}$ & $0.73 \times 10^{-3} \pm 0.53 \times 10^{-3}$ \\
\hline FC1 & $5.48 \times 10^{-3} \pm 0.87 \times 10^{-3}$ & $4.60 \times 10^{-3} \pm 0.97 \times 10^{-3}$ & $0.80 \times 10^{-3} \pm 0.87 \times 10^{-3}$ \\
\hline FC2 & $7.36 \times 10^{-3} \pm 3.39 \times 10^{-3}$ & $2.46 \times 10^{-3} \pm 0.86 \times 10^{-3}$ & $1.46 \times 10^{-3} \pm 0.64 \times 10^{-3}$ \\
\hline FC3 & $5.72 \times 10^{-3} \pm 1.13 \times 10^{-3}$ & $3.39 \times 10^{-3} \pm 0.76 \times 10^{-3}$ & $1.39 \times 10^{-3} \pm 0.85 \times 10^{-3}$ \\
\hline FC4 & $6.64 \times 10^{-3} \pm 0.75 \times 10^{-3}$ & $2.82 \times 10^{-3} \pm 0.12 \times 10^{-3}$ & $0.89 \times 10^{-3} \pm 0.97 \times 10^{-3}$ \\
\hline FC5 & $7.18 \times 10^{-3} \pm 0.97 \times 10^{-3}$ & $3.75 \times 10^{-3} \pm 0.53 \times 10^{-3}$ & $1.53 \times 10^{-3} \pm 0.75 \times 10^{-3}$ \\
\hline FC6 & $6.87 \times 10^{-3} \pm 1.39 \times 10^{-3}$ & $1.96 \times 10^{-3} \pm 0.93 \times 10^{-3}$ & $1.67 \times 10^{-3} \pm 0.13 \times 10^{-3}$ \\
\hline FC7 & $6.31 \times 10^{-3} \pm 1.53 \times 10^{-3}$ & $2.68 \times 10^{-3} \pm 0.85 \times 10^{-3}$ & $1.92 \times 10^{-3} \pm 0.37 \times 10^{-3}$ \\
\hline
\end{tabular}

${ }^{*}$ Average of three determinations, $\pm S D$ - Standard deviation $n=3$.

release profile of CLZ from patches was shown in Figures 7 and 8.

$\mathrm{FH} 4 \mathrm{c}, \mathrm{FH} 4 \mathrm{e}, \mathrm{FH} 4 \mathrm{~g}$-release of batch $\mathrm{FH} 4$ and FC4c, FC4e, FC4g -release of batch FC4 from celophan, egg membrane and goat mucosa, respectively.

In mucoadhesion study goat mucosa was used as biological membrane and study is carried out with the optimized batches only. Bioadhesive strength of the batch $\mathrm{FH} 4$ and FC4 was found to be $12.67 \pm 1.8 \mathrm{gm}$ and $10.38 \pm 2.3 \mathrm{gm}$, respectively. The force of adhesion was $0.0947 \mathrm{~N}, 0.0658 \mathrm{~N}$ and bond strength $638.56 \mathrm{Nm}^{-2}$, $503.39 \mathrm{Nm}^{-2}$, respectively for $\mathrm{FH} 4$ and FC4 batches (Table 6).

The release profile of different patches are as reported in Table 7. Patches shown matrix and Peppas release.

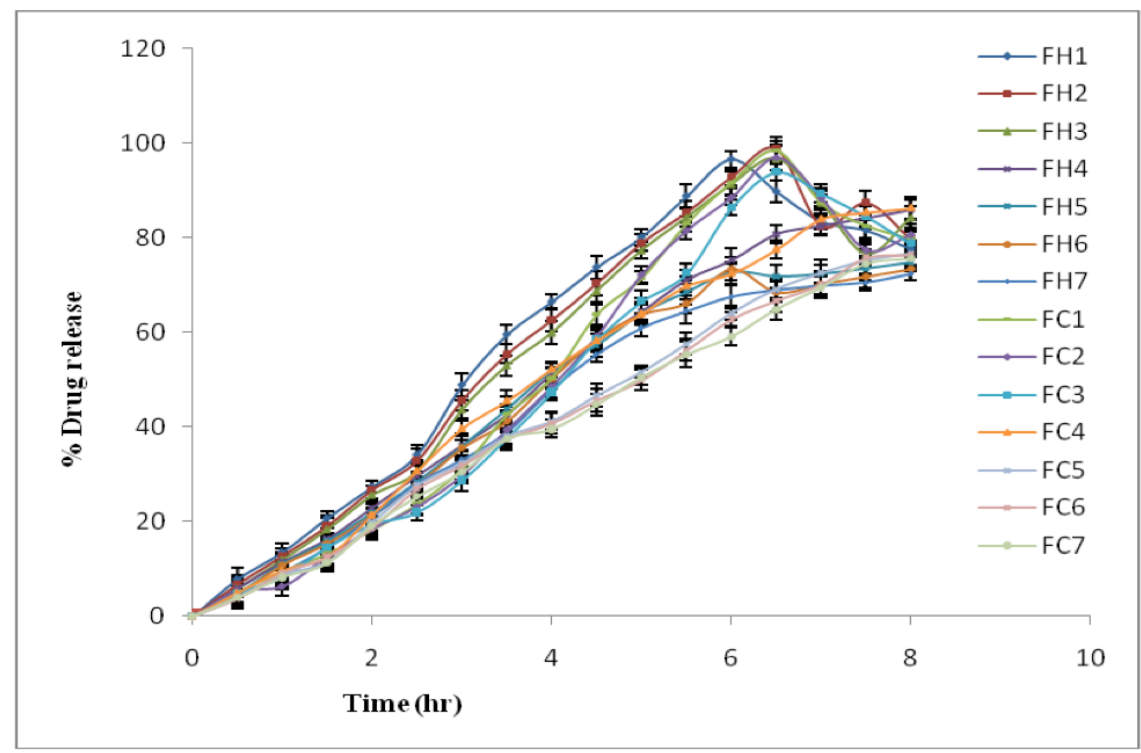

Figure 7: Release profile of CLZ from buccal patches on celophan membrane. 


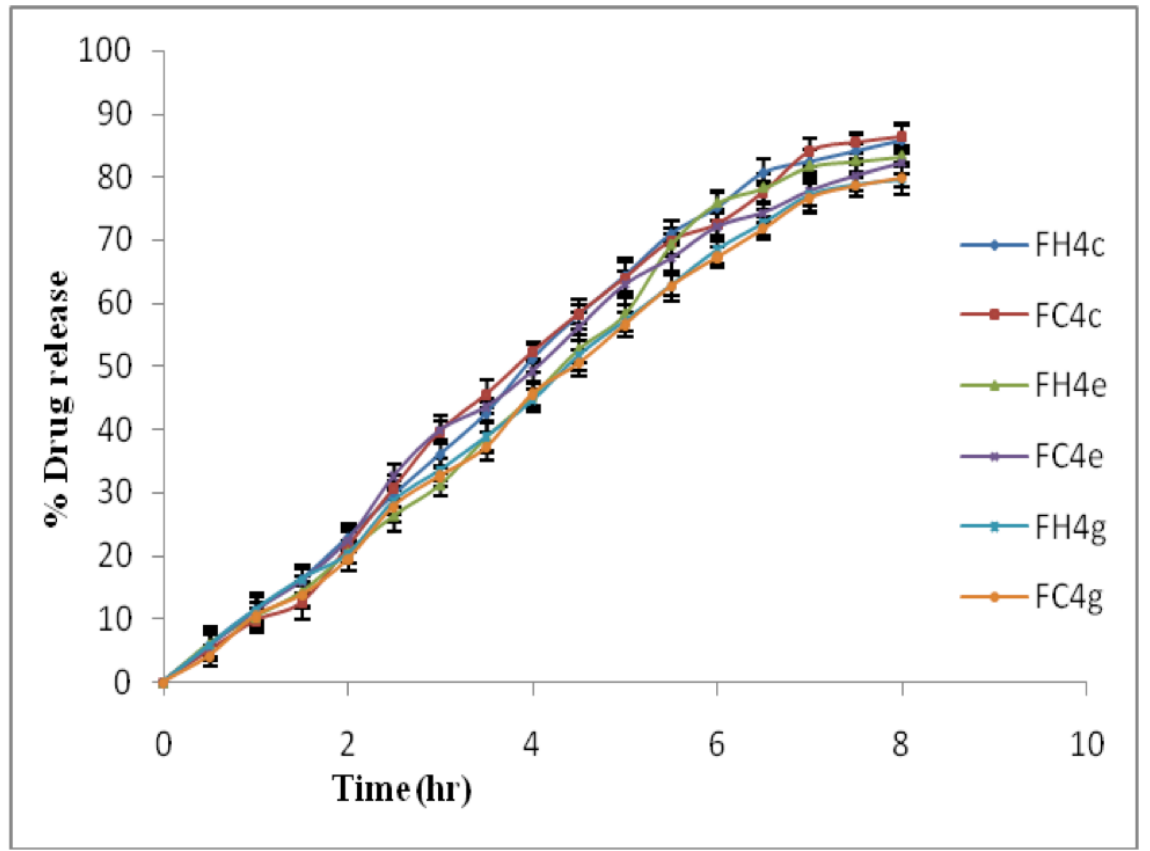

Figure 8: Release profile of CLZ from optimized batches of buccal patch on celophan, egg membrane and on goat mucosal membrane.

$\mathrm{FH} 4 \mathrm{c}, \mathrm{FH} 4 \mathrm{e}, \mathrm{FH} 4 \mathrm{~g}$-release of batch $\mathrm{FH} 4$ and FC4c, FC4e, FC4g -release of batch FC4 from celophan, egg membrane and goat mucosa, respectively.

Table 6: Physical, Mucoadhesive and In-Vitro Release Study of Buccal Patches

\begin{tabular}{|c|c|c|c|}
\hline Formulation code & Drug content \pm SD $^{*}(\%)$ & $\begin{array}{c}\text { In vitro residence time } \pm S^{*} \\
\text { (hr) }\end{array}$ & $\begin{array}{c}\text { Drug release after } 8 \mathbf{h r s}^{*} \text { on celophan } \pm \mathbf{S D}^{*} \\
(\%)\end{array}$ \\
\hline \hline Placebo H & - & $3.64 \pm 0.49$ & $77.57 \pm 1.721$ \\
\hline FH1 & $99.21 \pm 0.32$ & $3.27 \pm 0.74$ & $79.61 \pm 2.309$ \\
\hline FH2 & $99.04 \pm 0.13$ & $3.71 \pm 0.24$ & $84.35 \pm 2.367$ \\
\hline FH3 & $101.98 \pm 0.44$ & $2.54 \pm 0.82$ & $85.92 \pm 2.249$ \\
\hline FH4 & $97.44 \pm 0.36$ & $3.12 \pm 0.78$ & $74.78 \pm 2.413$ \\
\hline FH5 & $96.18 \pm 0.27$ & $2.85 \pm 0.39$ & $73.46 \pm 2.439$ \\
\hline FH6 & $98.07 \pm 0.45$ & $3.92 \pm 0.81$ & $72.69 \pm 1.973$ \\
\hline FH7 & $95.46 \pm 0.68$ & $2.62 \pm 0.41$ & - \\
\hline Placebo C & - & $3.82 \pm 0.26$ & $79.69 \pm 1.998$ \\
\hline FC1 & $99.01 \pm 0.53$ & $3.52 \pm 0.24$ & $80.75 \pm 1.888$ \\
\hline FC2 & $98.64 \pm 0.47$ & $2.88 \pm 0.29$ & $78.69 \pm 2.568$ \\
\hline FC3 & $101.67 \pm 0.23$ & $3.56 \pm 0.17$ & $86.26 \pm 2.316$ \\
\hline FC4 & $99.81 \pm 0.35$ & $2.58 \pm 0.43$ & $76.78 \pm 2.209$ \\
\hline FC5 & $100.64 \pm 1.44$ & $3.45 \pm 0.36$ & $76.38 \pm 2.369$ \\
\hline FC6 & $98.10 \pm 0.79$ & $3.67 \pm 0.97$ & $75.67 \pm 2.508$ \\
\hline FC7 & $97.98 \pm 0.32$ & $3.73 \pm 0.88$ & \\
\hline
\end{tabular}

*Average of three determinations, \pm SD - Standard deviation $n=3$.

\section{FTIR Study}

The IR spectra of the patch showed the same absorption bands as the solid dispersion, illustrating absence of interaction between CLZ with HPMC K4M and carbapol 974.

\section{Stability Study of Buccal Patch}

No significant changes were observed in drug content and diffusion study after 3 months. IR data indicated that there were no interactions of CLZ with the excipients with respect to time. Hence, patches can be kept for a period of one year or more. 
Table 7: Best Fit Model for Diffusion Study of Optimized Batches of Buccal Patch

\begin{tabular}{|c|c|c|c|c|}
\hline Sr. no. & Formulation code & Best Fit model & $\mathbf{n}$ & $\mathbf{R}^{2}=$ \\
\hline \hline 1 & FH4c & Matrix & 0.4796 & 0.9978 \\
\hline 2 & FH4e & Peppas & 0.3615 & 0.9943 \\
\hline 3 & FH4g & Peppas & 0.3241 & 0.9892 \\
\hline 4 & FC4c & Peppas & 0.3309 & 0.9959 \\
\hline 5 & FC4e & Matrix & 0.4072 & 0.9963 \\
\hline 6 & FC4g & Matrix & 0.4488 & 0.9984 \\
\hline
\end{tabular}

\section{CONCLUSION}

The solid dispersion system provides better control of drug release rate than the physical mixture at the same ratio of drug and polymer. The water-soluble carrier pluronic F127 and different techniques were investigated in the current study to formulate solid dispersion of CLZ, which enhanced the solubility and dissolution characteristics of the drug. The DSC, XRD and FTIR study had shown no interaction between CLZ and pluronic F127. The solid dispersion system is more efficient for preparation of CLZ sustained-release mucoadhesive buccal patches which can reduce first pass metabolism of the drug with improved dissolution.

\section{REFERENCES}

[1] Amidon $G$, lennernas $H$, Shah V, Crison J. A theoretical basic for a bio pharmaceutic drug classification: the correlation of in vitro drug product dissolution \& in vivo bioavailability. Pharm Res 1995; 12(3): 26-31. http://dx.doi.org/10.1023/A:1016212804288

[2] Emami J. In vitro - In vivo correlation: from theory to applications. J Pharm Pharmaceut Sci 2006; 9(2): 169-89.

[3] Susana A, Breda A, Kairuz J, Manzo R, Olivera M. Solubility behavior and biopharmaceutical classification of novel highsolubility ciprofloxacin and norfloxacin pharmaceutical derivatives. Int J Pharm 2009; 371: 106-13. http://dx.doi.org/10.1016/j.ijpharm.2008.12.026

[4] Guneri T, Taneri F, Ertan G. Studies on sustained release matrix systems of chlorzoxazone. Acta Pharmaceutica Turcica 2005; 47: 39-51.

[5] Karthikeyan V, Vaidhyalingam, Yuvaraj G, Rajesh K. Simultaneous estimation of paracetamol, chlorzoxazone and aceclofenac in pharmaceutical formulation by HPLC method. Int J ChemTech Res 2009; 1(3): 457-60.

[6] Jalali M, Valizadeh $\mathrm{H}$, Shadbad M, Adibkia K, Mohammadi G. Cogrinding as an approach to enhance dissolution rate of a poorly water-soluble drug (gliclazide). Powder Tech 2010; 197: 150-58.

http://dx.doi.org/10.1016/i.powtec.2009.09.008

[7] Lewis D, Udupa N, Atin K. Solid dispersions: a review. Pak J Pharm Sci 2009; 22(2): 234-46.

[8] Shin S-C, Cho C-W. Physicochemical characterization of piroxicam-poloxomer solid dispersion. Pharm Dev Tech 1997; 2(4): 403-407.

http://dx.doi.org/10.3109/10837459709022639
[9] Goddeeris C, Van den Mooter G. Free flowing solid dispersions of the anti-HIV drug UC 781 with poloxamer 407 and a maximum amount of TPGS 1000: investigating the relationship between physicochemical characteristics and dissolution behavior. Eur J Pharm Sci 2008; 13-18.

[10] Saritha A, Shastri N. Preparation, physico chemical characterization of solid dispersions of tenoxicam with poloxamer. J Pharm Sci Tech 2010; 2(9): 308-11.

[11] Cappello B, Giannini L, Mensitieri G, Miro A, Quaglia F, Russo R. Cyclodextrin-containing poly(ethylene oxide) tablets for the delivery of poorly soluble drugs: potential as buccal delivery system. Int J Pharm 2006; 319: 63-70. http://dx.doi.org/10.1016/j.ijpharm.2006.03.031

[12] Mario J, Becirevic-Lacan M. Influence of hydroxypropylcyclodextrin complexation on piroxicam release from buccoadhesive tablets. Eur J Pharm Sci 2004; 21: 251-60. http://dx.doi.org/10.1016/i.ejps.2003.10.029

[13] Gill B, Kaur T, Kumar S, Gupta G. Formulation and evaluation of glimepiride solid dispersion tablets. Asian $\mathrm{J}$ Pharm 2010; 4(3): 212-18. http://dx.doi.org/10.4103/0973-8398.72121

[14] Burgalassi S, Panichi L, Saettone M. Development and in vitrol in vivo testing of mucoadhesive buccal patches releasing benzydamine and lidocaine. Int J Pharm 1996; 133: 1-7. http://dx.doi.org/10.1016/0378-5173(95)04392-6

[15] Vishnu Y, Chandrasekhar K, Ramesh G, Rao Y. Development of mucoadhesive patches for buccal administration of carvedilol. Curr Drug Deliv 2007; 4: 27-39. http://dx.doi.org/10.2174/156720107779314785

[16] Luana P, Valeria A, Fausta A, Maurizio R, Stefano G, Marinella C, Carlo R. Development of mucoadhesive patches for buccal administration of ibuprofen. J Control Rel 2004; 99: 73-82.

\section{http://dx.doi.org/10.1016/j.jconrel.2004.06.005}

[17] Noha A, Fatma A, Boraie N, Mortada L. Mucoadhesive buccal patches of miconazole nitrate: in vitro/in vivo performance and effect of ageing. Int J Pharm 2003; 264: 114. http://dx.doi.org/10.1016/S0378-5173(03)00371-5

[18] Salamat-Miller N, Chittchang $M$, Johnston $T$. The use of mucoadhesive polymers in buccal drug delivery. Adv Drug Del Rev 2005; 57: 1666-91. http://dx.doi.org/10.1016/j.addr.2005.07.003

[19] Sudhakar Y, Kuotsu K, Bandyopadhyay A. Review buccal bioadhesive drug delivery - a promising option for orally less efficient drugs. J Control Rel 2006; 114: 15-40. http://dx.doi.org/10.1016/i.jconrel.2006.04.012 